\title{
Los discursos concurrentes que se convirtieron en rumor La designación como ejercicio de poder
}

\section{Concurrent speeches that became rumors The appointment as an exercise of power}

\author{
Autoras \\ Inesita Soares de Araujo \\ Orcid: 0000-0001-6927-5430 \\ Investigadora titular. Laboratorio de Investigación en Comunicación y Salud del Instituto \\ de Comunicación e Información Científica y Tecnológica Fundación Oswaldo Cruz \\ Brasil
}

Raquel Aguiar

Orcid: 0000-0002-6634-7758

Coordinadora de comunicación social del Instituto Oswaldo Cruz

Brasil

\section{Resumen}

Tomando como referencia empírica el modo por el cual las instituciones públicas de salud en Brasil reaccionaron a la intensa ola de informaciones no autorizadas que se propagó durante la epidemia del virus del zika y sus consecuencias neurológicas, de 2015 a 2016, el texto problematiza la designación de los discursos divergentes como "rumores". A partir de un acervo apoyado en la idea de la comunicación como un mercado simbólico y en la designación y modo de visibilidad como condición y modo de existencia pública, se discuten los enfrentamientos discursivos en torno a algunos temas polémicos, proponiendo el encuadramiento de los rumores como discursos concurrentes. El principal argumento para ello es que el encuadramiento de esos discursos como rumores es una estrategia que apunta a su descalificación y que la práctica caracteriza una forma de ejercicio de poder discursivo identificada con núcleos que por alguna razón se consideran voces autorizadas en la ciencia y/o en la salud. En

\section{Abstract}

Taking as an empirical reference the way in which public health institutions in Brazil reacted to the intense wave of unauthorized information that was propagated during the zika virus epidemic and its neurological consequences, from 2015 to 2016, the text problematizes the naming of divergent discourses as "rumors". Suported on a referential based on the idea of communication as a symbolic market and on the naming and mode of visibility as a condition and mode of public existence, discursive clashes on some controversial themes are discussed, proposing the framing of "rumors" as competing discourses. Their main argument is that the framing of these discourses as rumors is a strategy aimed at their disqualification and that the practice characterizes a form of exercise of discursive power identified with nuclei that for some reason are considered authorized voices in Science and/or Health. In contrast, calls for the recognition of these discourses as a place of plurality of meanings and the flow of 
contraposición, discute el reconocimiento de yearnings, expectations and social memories. esos discursos como lugar de la pluralidad de sentidos y del flujo de anhelos, expectativas y memorias sociales.

Palabras clave: comunicación y salud; Key-words: communication and health; rurumores; zika; microcefalia mors; zika; microcephaly

\section{Primeras aproximaciones}

El final del año 2015 estuvo marcado en Brasil por el reconocimiento de la relación entre el virus del zika, que avanzaba a partir de los estados de la Región Nordeste del país, y los casos de daños neurológicos y cognitivos en bebés nacidos de madres que habían sido infectadas durante la gestación, provocando un gran revuelo en el ámbito de la Salud Pública, revuelo que llegó a superar las barreras nacionales. Por ser un virus aún poco conocido y que presenta serias consecuencias en el feto, teniendo la microcefalia como su expresión icónica, desencadenó un proceso de desestabilización en el campo de la Salud Pública brasileña. La epidemia recibió el estatus de Emergencia en Salud Pública de Importancia Nacional, de noviembre de 2015 a mayo de 2017, período que fue marcado por un fuerte componente de incertidumbre asociado al virus; en el periodo reseñado se dio, además, una sucesión de anuncios de evidencias científicas, a veces contradictorias. Actualmente, se ha convenido la definición del síndrome congénita del zika, que puede estar asociada a manifestaciones neurológicas, ortopédicas y visuales, entre otras, en un amplio espectro de intensidad, de los casos más leves a los más graves.

El virus del zika promovió un efecto de desconstrucción de certezas en el área de la Salud Pública. En principio considerado benigno, como apuntan declaraciones de autoridades sanitarias, ganó, posteriormente, sentidos asociados al miedo y la inseguridad. En el caso del zika, la circulación de la producción simbólica tuvo su dinámica tradicional alterada, con acentuación de la interpenetración entre campos y cambios de protocolos operativos. En cuanto hecho epidemiológico, la circulación de un nuevo virus puede resultar en la producción discursiva en diversos géneros, tales como boletines, informes, planes de acción, comunicados de prensa y posts en redes sociales, retomando prácticas discursivas de diferentes campos. Por la urgencia del tema y por la amplia difusión de los medios nacionales e internacionales1, la divulgación de evidencias científicas por medio de publicaciones científicas revisadas por los pares - procedimiento típico del campo Científico, incorporado por el campo de la Salud - fue convertido en divulgación inmediata de los datos (Wellcome Trust, 2016), en un flujo continuo para los medios -y en los medios-, y, por lo tanto para la opinión pública y el debate sobre 'las contradicciones de la ciencia'.

En la medida en que se puso de relieve la incertidumbre en el espacio discursivo de la Ciencia y de la Salud Pública, de forma asociada al componente de hediondez de los efectos del virus y en un contexto marcado por la rapidez de circulación simbólica propiciada por las tecnologías digitales, el zika abrió un espacio oportuno para la circulación de discursos antagónicos al discurso oficial - concentrado, sobre todo, en el Ministerio de Salud (MS) y la Organización Mundial de la Salud (OMS) -, posibilitando la emergencia de una ola de "rumores" que exigió cambios discursivos en comparación con los discursos habituales en otras epidemias. 
Como otros investigadores de la Salud Pública en el país, nosotras también fuimos instadas a observar y acompañar ese movimiento a partir de nuestro lugar de pertenencia y actuación: un Laboratorio y un Grupo de Investigación con un Programa de postgrado, todos dedicados al estudio y enseñanza de la Comunicación y la Salud2, con vínculos con el Instituto Oswaldo Cruz (IOC / Fiocruz), que mantuvo un amplio dispositivo de comunicación con la prensa y la sociedad en el caso del zika.

Desde esa posición, pasamos a observar la dimensión comunicacional de la epidemia, con el objetivo de comprender y delinear las condiciones de la producción de sentidos sobre el virus y la sobre la propia epidemia. Comenzamos trazando una correlación entre la circulación viral y la circulación simbólica del zika y sus consecuencias, tomando como referencia la información en nueve periódicos impresos diarios en el país. Los resultados fueron presentados en dos publicaciones, estando la primera (Aguiar \& Araujo, 2016) dedicada a delinear las temporalidades, las especificidades y la conjugación de intereses en ese doble proceso de circulación, teniendo como ejes organizadores los conceptos de desigualdad y equidad. En el segundo estudio (Araujo \& Aguiar, 2017), profundizamos en el tema de la circulación discursiva, explorando la interpenetración e la interdependencia de los campos de la salud y el mediático, realzando el proceso de mediatización de las instituciones públicas de salud, enfatizando la incertidumbre como elemento central en las condiciones de producción simbólica del zika y haciendo una incursión exploratoria en el tema de los rumores, que culmina con una pauta temática de investigación comunicacional. Se analizaron, además de los periódicos anteriores, documentos informativos epidemiológicos, la tendencia de búsqueda de informaciones en el internet, la fanpage del MS en Facebook, viñetas de periódicos y los rumores predominantes en la fase inicial de la emergencia que provocó el zika.

El tercer trabajo (aún no publicado) fue presentado en un congreso internacional de semiótica - VIII Pentálogo Semiótica de los Medios, promovido por el Centro Internacional de Semiótica y Comunicación, en septiembre de 2017 - y contempló el modo de reconfiguración de la narrativa mediática sobre la microcefalia en el periodismo impreso por un grupo de madres de niños afectados por el virus a través de Facebook.

Nuestra intención es, continuando en la esfera de la epidemia del virus del zika, retomar el tema del "rumor" y discutir lo qué significa nombrar de esta forma un enunciado en circulación. En los trabajos anteriores este aspecto particular no fue problematizado y trabajamos de forma automática con esa designación - rumor - corriente en el ámbito de las instituciones de salud pública. Ahora nos disponemos a reflexionar sobre las implicaciones de descalificar una información, o argumento, a través de la clasificación de "rumor", término que remite, de forma automática, a la idea o argumento invertido y/o mal intencionado, que tiene por objetivo diseminar informaciones falsas acerca de un tema, personas o institución. Lo que pretendemos, sin embargo, no es hacer un juicio moral de ese o de aquel discurso, ni buscar identificar o distinguir lo que fue mala intención de lo que fue una versión no autorizada. Nuestra propuesta es tomar algunos episodios ocurridos en la epidemia del zika como anclaje para la discusión sobre el proceso de designación del discurso concurrente como rumor. En esa reflexión, partimos de algunos fundamentos teóricos ya desarrollados en otros trabajos y que aquí, articulados, formarán una perspectiva que oriente un modo de ver específico sobre el tema del rumor. 
Trabajar con el "rumor", tomando como referencia la comunicación con la sociedad de instituciones públicas de salud, en el marco de una epidemia, nos sitúa en la esfera disciplinar de la "comunicación pública". Esto pide una aclaración preliminar sobre lo que comprendemos por "público" cuando la palabra califica la comunicación4. Son dos los atributos que a nuestro ver hacen algo público. El primero, más evidente, es la circulación, pero con algunos condicionantes: es necesario una circulación amplia y con posibilidades de apropiación por todos los que de alguna forma están implicados o tienen interés en ella. Por esa premisa, lo que hace algo "público" no es del orden de la producción, sino de la circulación, con posibilidad de apropiación. Estamos operando, como se puede observar, con un concepto de comunicación como proceso de producción social de los sentidos que abarca producción, circulación y apropiación (Verón, 1980). El segundo atributo es que corresponda a una pluralidad de intereses, que sea por tanto fruto de un proceso que haya posibilitado la expresión y la escucha de intereses, de tal suerte que el polo que produce y hace circular una comunicación se puede presentar legítimamente como representante de intereses colectivos. En el mismo sentido, Monteiro (2007) resalta que lo que hará que la información se considere o no pública es si representa el interés colectivo, si es fruto del debate público y / o propicia el debate público.

\section{Puntos de anclaje}

Volviendo a los presupuestos teóricos, comencemos por la naturalización como una de las estrategias más eficaces en la lucha por la hegemonía de los sentidos, profundamente vinculado al acto de nombrar. Las cosas y hechos del mundo existen por su designación, que les da visibilidad y condición de existencia. Como Bakhtin (2006: 66) resalta, la palabra es "una arena en miniatura donde se entrecruzan y luchan los valores sociales de orientación contradictoria", constituyendo un "producto de la interacción viva de las fuerzas sociales". Es en la elección de las palabras, entonces, donde reside el microcosmos de la disputa de sentidos. En cierta medida, la designación asume el papel de clasificar el mundo, que opera en la dirección del cierre de los sentidos. Pinto destaca (1994: 82), desde el punto de vista comunicacional, que clasificar es "pedir al interlocutor que acepte las mismas designaciones para las mismas propiedades incautadas y hacer que compartir su manera de conceptualizar y organizar el universo (en suma, de compartir su construcción de sentido)". La clasificación, por lo tanto, es parte de una búsqueda de homogeneizar el sentido.

La visibilidad conferida por el acto de designación no es un valor en sí, ya que no siempre es positiva, pudiendo también descalificar, producir discriminación, hasta resultar en estigma, del mismo modo que puede imputar un valor positivo. Mucho más que simple elección lexical, la designación produce, entonces, efecto sobre las personas y sobre las relaciones sociales, tanto más cuanto se naturaliza en el lenguaje, es decir, la designación se vuelve de uso tan corriente que sus condiciones originales de producción ya no son visibles o reconocibles.

Esto sólo es posible porque quien nombra está (o estuvo, originalmente) investido de legitimidad, siendo reconocido como una "voz autorizada" en su ámbito de circulación discursiva. En los términos de Bourdieu (2011), estamos hablando de poder simbólico, el poder de hacer ver y de hacer creer, de constituir lo dado por la enunciación. Este poder sólo puede ser efectivamente ejercido, dice Bourdieu, cuando se ignora su arbitrariedad, de la misma forma como el reconocimiento de la arbitrariedad es indispensable para un cambio en las relaciones que él implanta y fundamenta, empezando por la desnaturalización de las propias designaciones. 
En el ámbito de las relaciones personales, la comprensión de este proceso es fundamental en la lucha por la identidad y por mejores lugares de interlocución. Es lo que viene ocurriendo en todo el mundo en relación a los grupos y movimientos sociales, que protagonizan disputas ancladas en la noción de derecho a definir su propio modo de visibilidad, por lo tanto, de existencia pública. El lugar de interlocución (Araujo, 2003) es un concepto que ayuda a profundizar esa comprensión, al referirse a la posición que cada uno ocupa en el acto comunicacional. Siendo un lugar relacional, definido por la relación con el interlocutor, codetermina la cuota de poder simbólico de las partes, incluyendo el derecho de establecer las designaciones

Las disputas por el poder de nombrar (incluso el poder definitorio de la "verdad de los hechos") ocurren en el ámbito discursivo, producen y hacen circular discursos concurrentes (Verón, 1980 y 2003) que, por una perspectiva de la comunicación como proceso productivo de negociación, pueden ser vistos como participantes de un mercado simbólico. Las instituciones que practican la comunicación pública compiten en estos mercados, haciendo circular sus discursos que disputan la prerrogativa de ser portadores de informaciones verdaderas y necesarias. Cuando se trata de temas que afectan la salud pública, por ejemplo, epidemias, estas instituciones son voces tradicionalmente autorizadas, investidas de legitimidad para establecer e informar sobre la situación en pauta. Cuando se trata de instituciones científicas, esos enunciados tienen, aún, la legitimidad que emana del propio campo de la ciencia. Es entonces cuando a los discursos disonantes, se puede aplicar la designación de "rumores".

\section{Lo que se dice sobre el rumor}

El rumor es un tema que atrae mucha atención, desde su recrudecimiento con las tecnologías asociadas al surgimiento de las redes sociales digitales, dado que imprimen una gran velocidad en la diseminación de cualquier discurso y han demostrado un gran poder para fomentar la disputa discursiva en torno a temas polémicos. Hay muchos blogs que tratan de esta temática, que crean tipologías o listan características para el reconocimiento de los rumores, establecen estrategias para la defensa contra sus efectos, traen estadísticas sobre credibilidad, crean sellos de calidad, entre otros enfoques. Hay incluso páginas de Internet que se dedican a investigar rumores que circulan en las redes, buscando su veracidad (por lo tanto, buscando clasificarlos como rumores). Incluso Umberto Eco dedica al tema una novela, Número Cero.

Todo este interés es justificable, si consideramos algunos datos, como el de la investigación de la Escuela de Computación Interactiva del Instituto de Tecnología de Georgia (Atlanta, EE.UU.): el $23,46 \%$ de los tweets en el mundo no son creíbles (Sá, 2015). Por otro lado, prácticas como la construcción de perfiles falsos para intervenir en procesos colectivos (como los procesos electorales, que tal vez sean el ejemplo más emblemático) e incluso robots que manipulan las manifestaciones en las redes sociales, se están volviendo corrientes. Las investigaciones se multiplican sobre la credibilidad de las fuentes, con resultados a menudo divergentes, que oscilan entre el descrédito a todo lo que vendría de redes sociales y la confianza incondicional, siempre que la fuente más cercana sea conocida o que el enunciado sea convergente con un posicionamiento u opinión previos.

Sin embargo, pocos trabajos sistemáticos buscan un marco teórico y, menos aún, metodológico para trabajar el rumor. Destacamos aquí el enfoque de la lingüista Eni Orlandi (2012) que, en una definición discursiva, caracteriza el rumor como un hecho público del lenguaje. A partir 
de su noción de silencio como lugar del sentido, Orlandi argumenta que el rumor significa por el silenciamiento, por la ausencia de un decir explícito, de una autoría sustituida por el impreciso "se dice que". Pero también explica su existencia debido a los márgenes de explotación de cualquier información, por la duda que es constitutiva de todo saber o opinión, poniendo así el rumor en la situación de producir efectos de verdad a partir de lo que no se ha dicho, no ha sido confirmado por ninguna voz autorizada que tiene legitimidad para apuntar "la verdad de los hechos". Por otro lado, la autora ofrece sustentación a nuestra perspectiva, al decir que el rumor es una evidencia de la disputa de sentidos, en la que podría ser un recurso para cualquiera de los lados, sea para dominación, sea para resistencia. En ese sentido, Orlandi afirma que el rumor es el grado cero de la política.

Esto nos coloca en el territorio de la hegemonía de los sentidos, que se vale, entre otros recursos, de la designación para caracterizar los discursos disonantes, antagónicos y/o desfavorables - en nuestro tema, la designación de un discurso como "rumor"-. En el reverso de la moneda, hacer circular un contradiscurso puede ser estrategia de quien está en posiciones discursivas periféricas.

\section{4. ¿Rumor, contradiscurso o discurso concurrente?}

En la disputa de designaciones, observamos el uso de diferentes términos para nombrar los mismos fenómenos, siendo los más frecuentes contradiscurso y contranarrativa. Aunque todo "rumor" es un contradiscurso, de la misma forma que una contranarrativa, ambos pueden designar otros discursos no necesariamente antagónicos al discurso hegemónico.

Contradiscurso es la negación de un discurso en circulación, en cualquier circunstancia, pudiendo incluso referirse a los discursos que pretenden negar un "rumor" y restablecer la "verdad de los hechos". El término puede también designar una construcción discursiva alternativa, sin necesariamente representar un antagonismo o disputa explícita. En el trabajo anterior (Araujo \& Aguiar, 2017), al estudiar comparativamente la narrativa periodística y la de un grupo de madres de niños con microcefalia sobre sí mismas y sobre sus hijos, pudimos constatar, por un lado, que las madres rechazaban la identidad de sufrientes con que las caracterizaban la prensa, al tratarse de personas especiales por tener "ángeles" a sus cuidados, por los cuales sienten intenso amor y, por otro, como ciudadanas, luchadoras, conscientes de sus derechos y capaces de exigirlos a los poderes públicos. Hacían circular, así, por la red social Facebook, un contradiscurso sobre sí mismas y sus hijos, que de víctimas pasaban a ser ángeles y de motivo de sufrimiento a razón de alegría.

Por su parte, la contranarrativa, expresando lo mismo aunque de manera contradictoria, a menudo ha sido utilizada para referirse a estrategias discursivas de lucha contra los discursos de segregación y/o de odio en las redes sociales digitales e Internet de un modo general, generando un movimiento que se apoya en respeto de la diversidad de opiniones. Sus antenas están dirigidas a temas como la homofobia, el sexismo, el racismo, la xenofobia, la intolerancia religiosa y política y todas las formas de discriminación.

Por nuestra parte, queremos proponer otro marco para el "rumor", el de discurso concurrente, retomando la idea de la existencia de un mercado simbólico, lugar de negociaciones discursivas que, dependiendo de los contextos de producción y circulación, se dibujan como luchas. Los rumores siempre serán contradiscursos, porque se enuncian en relación a otro; y, en senti- 
do amplio, serán siempre contranarrativas, en la medida en que relatan el mismo hecho desde otro modo de ver y decir. Siendo, sin embargo, una categoría más amplia, el discurso concurrente instaura la posibilidad de percibir con más nitidez la idea de una disputa de sentidos, en la cual no inciden sólo los discursos en confrontación, sino un amplio conjunto de variables contextuales que pueden definir las posibilidades de predominio de éste o de aquel punto de vista. Por otro lado, permite disolver la carga negativa y descalificadora del término "rumor", invertido del sentido de "falso", "mentiroso" o "mal intencionado".

Es con esta perspectiva que pasamos a analizar algunos hechos ocurridos durante la epidemia del virus del zika, entre noviembre de 2015, cuando hubo la declaración de Emergencia en Salud Pública de Importancia Nacional, y los primeros meses de 2016, buscando conferir materialidad empírica a nuestro argumento de que la clasificación de un discurso concurrente como "rumor" caracteriza el ejercicio del poder de nombrar discursivamente al otro, poder que emanaba de voces autorizadas y hegemónicas sobre un tema.

\section{El rumor en la epidemia del zika}

Las condiciones de producción y circulación de los discursos concurrentes en la epidemia del virus del zika y de la microcefalia, acentuados e intensificados por las tecnologías y los medios digitales, principalmente las redes sociales y los blogs, hicieron que se verificara una verdadera batalla discursiva en torno a la "verdad de los hechos". Los ataques ocurrieron en páginas de Facebook, blogs y portales de las autoridades sanitarias, pero también por audios compartidos en aplicaciones de intercambio instantáneo de mensajes, como Whatsapp, en páginas individuales de Facebook y en espacios digitales noticiosos de otros actores sociales. Aunque no es posible aseverarlo con certeza, teniendo en cuenta las dificultades metodológicas para dar cuenta de un mapeo exhaustivo que retrate los múltiples caminos de los enunciados, hay algunas evidencias de una circulación más intensa de los discursos concurrentes a los oficiales, principalmente a través de las redes sociales. Un estudio que partió de más de 100 mil posts en Twitter sobre el virus ébola constató que las informaciones tenidas como "falsas" circularon tres veces más que las que intentaban corregirlas (American Press Institute, 2015). Otro estudio de Sharma y colaboradores (Sharma, Yadav, Yadav, Ferdinand, 2017) sobre los posts en inglés sobre zika en Facebook, teniendo como referencia una semana de junio de 2016, mostró que el volumen de visualizaciones de publicaciones de instituciones como la OMS fue muy reducido en relación a las posturas basadas en rumors - nada menos que una diferencia entre 43 mil y 530 mil visualizaciones-.

En Brasil, el MS, a diferencia de lo ocurrido en epidemias anteriores, adoptó un protocolo que no permitía ignorar la existencia de discursos concurrentes. De acuerdo con un documento que definía la estrategia del gobierno federal para responder al zika (Estratégia de resposta ao vírus Zika e combate ao mosquito transmissor, 2016: 87), la "comunicación con la población" debería guiarse en dos elementos fundamentales en lo que se refiere a rumores: por un lado, "ser "fuente única de la verdad" en la comunicación de información científica de las medidas de control de infección y de las más recientes políticas y procedimientos para los profesionales de la salud" y, por otro, "identificar y corregir la desinformación".

Si antes predominaba la estrategia de divulgar la "verdad de los hechos", silenciando los discursos concurrentes, en la epidemia del zika y de la microcefalia se adoptó la práctica de enun- 
ciar la versión antagónica o divergente, para entonces descalificarla, como rumor, o como mito. Desde el punto de vista de la producción discursiva de los sentidos sociales, esto representa un cambio importante: el silencio sobre el adversario es más contundentemente que promover la visibilidad del adversario para luego deslegitimárselo, como nos alerta Orlandi (2010). La autora, incluso, llama la atención sobre la palabra "interdicto", expresando que el decir que fue negado adquiere otra forma de decir y significa en las entrelíneas. Sin embargo, nuestras investigaciones nos han mostrado que una réplica de una voz autorizada sobre un discurso concurrente no necesariamente reduce dicho discurso, pudiendo incluso ser combustible para suscitar contrarréplica, instaurándose un debate que, si es saludable y bienvenido los términos de un debate público, potencian la circulación del discurso concurrente.

En el estudio anterior mencionado (Araujo \& Aguiar, 2017), identificamos la circulación de discursos concurrentes abordando los siguientes temas principales:

- Relación entre los casos de microcefalia y los lotes estropeados de la vacuna de rubeola.

- Secuelas neurológicas del zika entre ancianos y niños hasta siete años.

- Asociación causal entre la microcefalia y dos experimentos científicos en marcha en el país: la liberación de mosquitos transgénicos y de mosquitos con la bacteria wolbachia.

- Zika fue creado por corporaciones extranjeras para permitir el posterior lucro con vacunas y medicamentos.

- Los médicos cubanos del programa Más Médicos del gobierno federal trajeron el virus (con una variante de un plan maquiavélico para "cubanizar" Brasil).

- Los inmigrantes haitianos trajeron el virus.

Adicionalmente, podemos citar la reacción al cambio de los criterios adoptados por el MS para definir el perímetro encefálico relacionado a la microcefalia, con la especulación de que el objetivo sería minimizar las estadísticas de casos. Otros dos discursos circularon con raíz en grupos vinculados a la salud colectiva, pero no del Ministerio de Salud, y también fueron objeto de disputas. Uno fue sobre la presencia de un larvicida en el agua que abastece a las ciudades con mayor número de casos de microcefalia, sugiriendo relación directa con el síndrome. Otro, una divergencia de grupos científicos en cuanto a la posibilidad de otro mosquito que no el Aedes aegypti - el Culex quinquefasciatus, endémico sobre todo en la región Nordeste de Brasil, epicentro de los casos de microcefalia - también pudiera ser responsable por la transmisión del virus. En estos casos no estamos hablando de rumores sino de discursos concurrentes. Los discursos que hicieron circular enunciados con voces identificadas, pautados en documentos y que involucraron entrevistas colectivas, releases y artículos científicos.

En la secuencia que ven a continuación, mostramos algunos ejemplos de imágenes de esa pelea discursiva que ha envuelto al zika y a la microcefalia. Las imágenes del 1 al 5 son del Ministerio de la Salud: 1, 2, y 3 son posts publicados en su fanpage en Facebook, siendo las dos primeras referentes a la cuestión en torno a las vacunas; la imagen 4 tiene como referente los daños neurológicos en niños y ancianos y la imagen 5 enfoca el tema de los criterios de definición del perímetro encefálico para categorización de casos de microcefalia. Las imágenes 6 , 7 y 8 son ejemplos de discursos emanados de otras fuentes autorizadas (universidad, centros de investigación, medios, etc.), verificándose el mismo efecto de invalidación de discursos concurrentes. 
Figura 1 - Post del Ministerio de Salud en Facebook sobre rumor referente a la vacuna (11 diciembre 2015) Fuente: Fanpage del MS en Facebook.

Ministério da Saúde

11 de dezembro de $2015 \cdot$

É importante evitar boatos e especulaçōes. Reforçamos que as únicas vacinas recomendadas durante a gestação sāo:

- DT

- DTPA

- HEPATITE B

- Gripe, quando em campanha... Ver mais

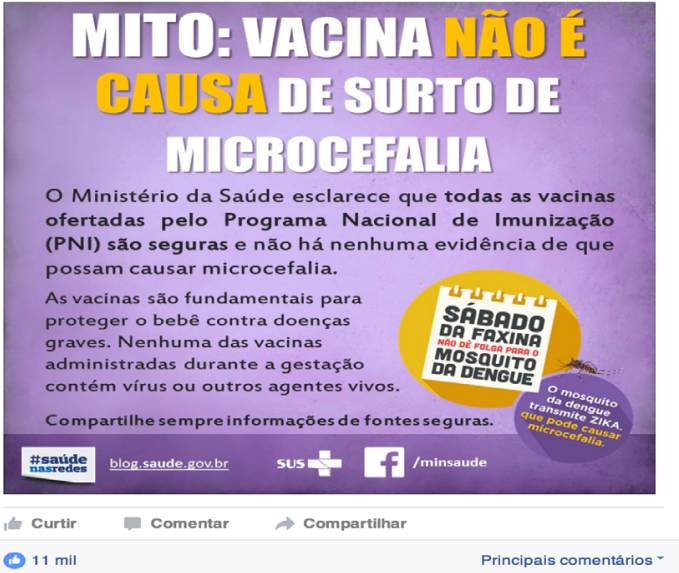

Figura 2 - Post del Ministerio de Salud en Facebook sobre boato referente a la vacuna (31 diciembre 2015) Fuente: Fanpage del MS en Facebook.

Pinistério da Saúde compartilhou o vídeo de Portal

Brasil

31 de dezembro de $2015 \cdot 0$

Não acredite em tudo que escuta por ail

Tem gente dizendo que vacina contra rubéola causa microcefalia, mas isso não é verdade! Compreenda melhor esse boato e

\#CompartilheaVerdade! www.fatoseboatos.gov.br

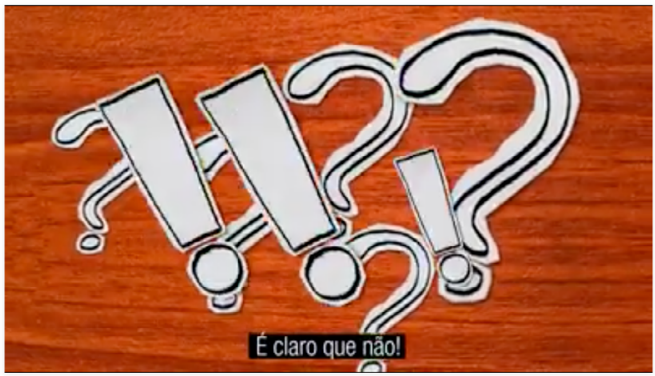

28.114 visualizaçōes

\section{Portal Brasil}

30 de dezembro de 2015 .

Curtir Página

Năo acredite em tudo que escuta por ail

Tem gente dizendo que vacina contra rubéola causa microcefalia, mas isso não é

verdade! Compreenda melhor esse boato e \#CompartilheaVerdade!

www.fatoseboatos.gov.b

If Curtir $\quad$ Comentar $\Rightarrow$ Compartilhar 
Figura 3 - Post del Ministerio de Salud en Facebook sobre boato referente a la vacuna (5 enero 2016) Fuente: Fanpage del MS en Facebook.

Х. Ministério da Saúde compartilhou o vídeo de Palácio do

Planalto.

5 de janeiro $\cdot 0$

É boato!

Andam dizendo que o surto de microcefalia está relacionado com a

vacinação de rubéola e não com o Zika virus. Mas isso é mentira! Acesse http://goo.gl/xklEX9 e ajude a esclarecer essa questão. Assista ao vídeo e compartilhe a verdade!

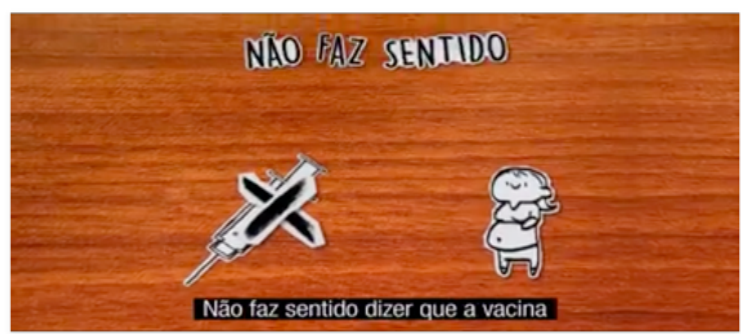

\subsection{0 visualizaçōes}

Palácio do Planalto

4 de janeiro $\cdot 9$

It Curtir Página

É boatol

Andam dizendo que o surto de microcefalia está relacionado com a vacinação de

rubéola e não com o Zika virus. Mas isso é mentira! Acesse http://goo.gl/xklEX9 e

ajude a esclarecer essa questâo. Assista ao vídeo e compartilhe a verdade!
In Curtir
Comentar
$\rightarrow$ Compartilihar

(1) 943

Principais comentários *

Figura 4 - Post del Ministerio de Salud en Facebook sobre boato referente a daños neurológicos en niños y ancianos (2 febrero 2016) Fuente: Fanpage del MS en Facebook.

Boatos falsos sobre a infecção pelo virus Zika ainda circulam por whatsapp. Para tirar dúvidas sobre o tema, siga as nossas redes sociais e visite o site http://combateaedes.saude.gov.br/. Busque sempre informaçōes de fonte segura! \#CombateAedes
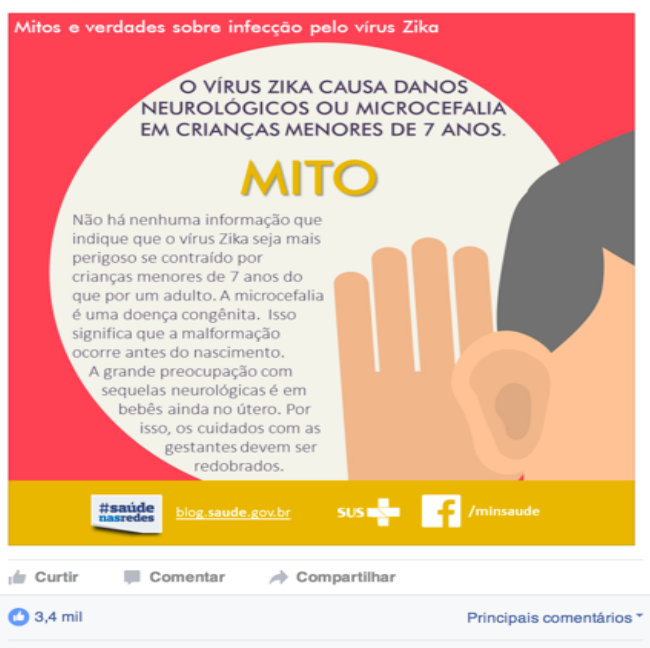
Figura 5 - Post del Ministerio de Salud en Facebook sobre boato referente a criterios de definición del perímetro encefálico (30 diciembre 2015) Fuente: Fanpage del MS en Facebook

Ministério da Saúde

30 de dezembro de 2015 -

É muito importante evitar boatos. A adoção da medida do perímetro

cefálico preconizada pela OMS evita que bebês sem a malformação sejam

submetidos a uma série de exames desnecessários. Compartilhe

informaçōes de fontes seguras! \#CombateAedes \#CombataDengue

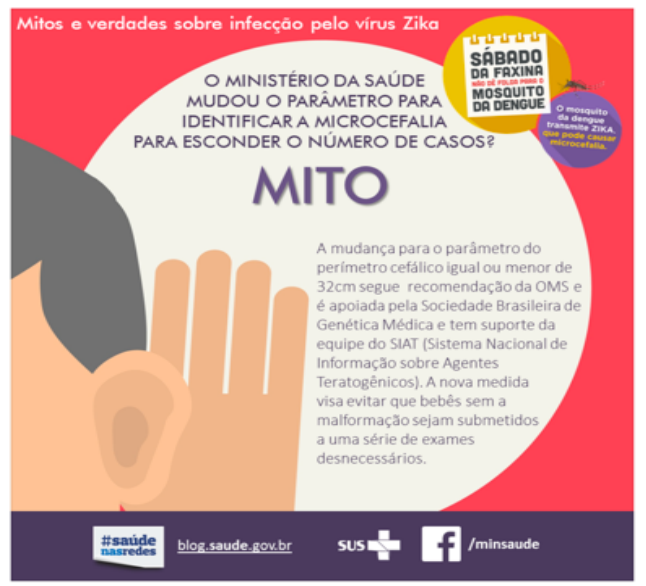

Ith Curtir $\quad \rightarrow$ Compartilhar

780

Principais comentários

472 compartilhamentos

Figura 6 - Título de noticia con énfasis en "desmentido" por la Fiocruz (9 diciembre 2015) Fuente: Agência Brasil.

Geral

Fiocruz desmente boatos de que Zika

cause problemas neurológicos em

crianças 
Figura 7 - Título de noticia con énfasis en "desmentido" por la Fiocruz y el Ministerio de Salud (9 diciembre 2015) Fuente: G1.

\title{
三 MENu GIO DE JANEIRO
}

\section{Fiocruz e Ministério da Saúde desmentem boatos sobre zika vírus}

Informações equivocadas têm circulado nas redes sociais.

Postagens dizem que o vírus causa lesão neurológica em crianças e idosos.

\author{
Figura 8 - Título de noticia con énfasis en "desmentido" por la Universidad de São Paulo \\ (18 deciembre 2015) Fuente: Website de la Universidad de São Paulo.
}

\section{Especialistas da USP desmentem boatos sobre o Zika}

Como se puede observar en los ejemplos, la respuesta de las voces autorizadas a la circulación de discursos antagónicos fue la de clasificar los discursos concurrentes como rumores, mitos o mentiras, todas designaciones que descalifican, reivindicando para sí la competencia de la "verdad de los hechos", o sea, información verídica que puede "desmentir" las noticias falsas.

Los discursos que circularon con versiones sobre el zika y la microcefalia divergentes de las versiones oficiales no eran todos de la misma naturaleza, siendo algunos bien intencionados, otros frutos de visiones conspiratorias, otros incluso frutos de una mentira mal intencionada y otros aún resultantes de visiones científicas o sanitarias distintas de la hegemónica. Además de esa vinculación a la epidemia y sus desdoblamientos, los "rumores" florecen cuando hay incertidumbre, miedo, inseguridad, que lleva a la desconfianza, tanto más cuando las fuentes oficiales son los únicos enunciadores autorizados o el conocimiento científico sobre el tema es insuficiente. El zika y la microcefalia caben perfectamente dentro de todos estos criterios, pero a ellos no se restringen y destacamos algunos.

Entre los cambios acarreados por la epidemia del zika, uno importante fue la introducción por el MS de un protocolo de reacción a la circulación de los discursos antagónicos, que incluía la ya citada actitud de reconocer públicamente el enunciado divergente, citándolo para entonces invalidarlo, pero también de buscar aclarar por varios medios a todas las dudas. También se reconoció las diferentes exigencias de los diferentes medios, tanto es así que se creó una campaña específica para Facebook. Por otro lado, volvieron a utilizar el enfoque de Mitos versus Verdades, ya asumida en campañas anteriores relacionadas con situaciones como la origina por el ébola, la vacuna del VPH y el uso del preservativo. La Fundación Oswaldo Cruz, institución científica vinculada al MS, domo fuente para la prensa, trató el rumor como "información 
equivocada" y clasificando su propia voz como "desmentido". El rumor fue así reconocido en su condición de género informacional, pero inmediatamente descalificado por su incorrección. Una condición de producción de los rumores, que se ha mostrado importante en otras epidemias, pero que en la del virus del zika se acentuó extraordinariamente, se refiere a la discrepancia de temporalidades entre los hechos empíricos, los medios y la ciencia. Los sistemas de alerta son diferentes y con tiempos propios. Cuando la ciencia es presionada por los medios (que, a su vez, es presionada por la población afectada y alarmada por los hechos) está obligada a operar con otra temporalidad, y entonces ocurre lo que se entiende como la "salud pautada por los medios". En el caso de la epidemia del zika, esa presión - que desde las instituciones públicas de salud se vivió con poco conocimiento sobre el virus y sus compromisos - fue de tal orden que se alteró el orden canónico de circulación discursiva entre campos. Así, por ejemplo, antes incluso de que se pudiera organizar un boletín epidemiológico, existía la necesidad de conceder entrevistas, divulgar notas de prensa a los medios y otros procedimientos propios del campo periodístico. La mayor evidencia de esta reorganización temporal, a nivel global, fue ya citado protocolo de intercambio de datos. Los resultados de investigaciones ganaban publicidad antes de pasar por el procedimiento más consolidado de la ciencia, que es pautado en la revisión por los pares.

En estas circunstancias, los inevitables desencuentros y disonancias entre las propias autoridades sanitarias aumentaron el grado de incertidumbre de la población que, con las comunicaciones digitales, pasó a actuar más proactivamente en el ámbito discursivo, dando densidad y complejidad al mercado simbólico de los sentidos del zika y de la microcefalia.

Otra condición de producción importante fue el que la epidemia ocurre en un escenario de desconfianza general en las instituciones, en un período simultáneo al golpe/impeachment (también aquí los discursos concurrentes son centrales) de la presidente de la República, acompañado por un proceso de rápido desmoronamiento de la credibilidad en los poderes públicos. El hecho de que las informaciones sobre la epidemia fueran centralizadas en un órgano de la estructura del gobierno federal, el MS, se asociaba de forma negativa con ese cuadro, poniendo a priori bajo sospecha lo que podría emanar de allí.

Un aspecto adicional que queremos mencionar es la intensa interdiscursividad manifestada en los discursos antagónicos a los discursos oficiales, fenómeno ya estudiado ampliamente en otras epidemias (Cardoso \& Vaz, 2014; Malinverni, 2017). Intertexto es discurso en movimiento y en el va y viene de la memoria que promueve, abre un espacio acogedor para la proliferación de "versiones no autorizadas", pero que se apoyan en una experiencia discursiva y existencial anterior. Así, en los rumores relacionados con vacunas estropeadas, percibimos sentidos presentes en el movimiento antivacuna, diseminado ya internacionalmente, y en esta caso, vacunas estropeadas, destinadas a Pernambuco, estado situado en la región Nordeste. Algunos rumores, como los que culpabilizan a los inmigrantes y los médicos cubanos, se alimentan de estereotipos, además de un discurso contra el Partido del Trabajo y anticomunista. También estuvieron presentes discursos que se contraponen a los intereses económicos en el sector de la salud y de los grandes laboratorios, así como se manifestó con contundencia el descrédito en los actos de los gobiernos, siendo constitutivos de la sospechosa sobre los mosquitos transgénicos y las vacuna. En el rumor sobre la creación intencional y posterior liberación del virus por corporaciones extranjeras, emerge la crítica a la mercantilización de la salud -en 
última instancia, un discurso crítico con el capitalismo-. La lista de intertextualidades, como se ve, es bastante extensa.

Por otro lado, queremos subrayar una última condición favorable a la producción y circulación de rumores: el predominio de una comunicación pública que se basa en el modelo del déficit cognitivo, pautada en un conjunto de informaciones que se supone debería ser transferido a los ciudadanos. Tal vez por eso la designación como "rumor" por fuentes ampliamente autorizadas no sea suficiente para interrumpir la circulación de discursos concurrentes.

Por último, merecen tener en cuenta las referencias, en los discursos concurrentes, a supuestas fuentes de las informaciones, como personas con acceso privilegiado a circuitos legitimados, evidenciando la persistencia de una perspectiva conspiratoria, que sostiene que las instancias oficiales esconden algo que debería ser de conocimiento público, asumiendo así un carácter de denuncia en favor de la transparencia.

En una investigación de maestría enfocando los rumores sobre el zika y la microcefalia en las redes sociales, Garcia (2017) añade más elementos al análisis del fenómeno, entre los que destacamos el aspecto de que "las narrativas alternativas mantuvieron una ambigua relación con la autoridad científica, contradiciéndola, buscando legitimidad en la mención a instituciones y especialistas". Garcia (2017: 209) concluye que, en ambientes digitales caracterizados por la conversación y la mediatización, "las opiniones de los individuos circulan como comentarios casi en pie de igualdad con el discurso técnico y científico".

\section{Retomando el hillo de nuestra mirada}

Iniciamos este texto hablando de que la epidemia del zika provocó una gran desestabilización en las certezas y en las prácticas del campo de la salud pública. Una de las características de este proceso fue la intensa circulación de enunciados sobre el virus y sus consecuencias, principalmente la microcefalia, enunciados que fueron descalificados por las voces autorizadas en salud pública, que los consideraron rumores, mitos o informaciones falsas.

Sin la pretensión de discutir su veracidad como información científica, tratamos de entender mejor la relación discursiva establecida entre los que están legalmente y / o legítimamente investidos del poder de establecer la verdad sobre los hechos científicos y sanitarios y los que, estando en la periferia de los sentidos, buscan disputar espacio en el mercado simbólico de la salud, específicamente de la epidemia del zika y de la microcefalia. Estos discursos concurrentes casi nunca surgen de forma organizada, como expresión de un grupo, sino por numerosas voces espontáneas y simultáneas, convergentes. En el episodio del zika, circulando intensamente en el ámbito digital, su fuerza fue enriquecida intertextualmente por una memoria discursivo existencial y contextualmente por una situación de incertidumbre científica, siendo amplificada por el escenario político nacional.

Argumentamos también que el término "rumor" es atribuido a los discursos periféricos por los que están en posiciones más centrales del reparto de los poderes discursivos. En el caso del zika, se caracterizó un dispositivo predominante de descalificación de discursos en vez de silenciar el discurso concurrente. 
La discusión en torno a los sentidos del zika y de la microcefalia puede estar comprendida en otras, de mayor amplitud. El concepto de ciencia ciudadana fue abordado por Manso (2015), en busca de una nueva comprensión sobre ciencia y sus flujos informacionales. En este sentido, dice:

"En este complejo espacio de mediación entre pluralidad de voces y de pugnas discursivas, surge la oportunidad de actuación más incisiva de personajes no típicamente académicos asumiendo una posición y un estatus estratégicos en los debates, por lo que encuentran la posibilidad de orientar el desarrollo científico, social y humano, así como de reconfigurar todo el flujo tradicional de producción y comunicación científicas". (Manso, 2015:1)

Aunque el autor está tratando de la Comunicación Pública de la Ciencia, sus consideraciones ayudan a pensar la Comunicación Pública en tiempos de epidemias.

"La pretensión es combinar los más diversos tipos de saberes cotidianos sociales, las experiencias vividas en el día a día, con los saberes científicos formales. Esta hibridación motiva la creación de términos variados, como ciencia post-académica (ZIMAN, 2000) y ciencia modo 2 (GIBBONS, 1994). Los conceptos y teorías buscan dar cuenta de estos procesos, que también pueden ser analizados desde el punto de vista de los conflictos sociales por el poder, el prestigio, La posición social y la hegemonía de narrativa en formación y en circulación en los espacios públicos (y también privados)". (Manso, 2015: 2)

Los discursos concurrentes sobre los temas del zika y de la microcefalia hacen públicos la pluralidad de sentidos, ponen en escena saberes, percepciones, necesidades, perspectivas y expectativas de amplias parcelas de la población - como ya dijimos, en una mezcla de buenas y de malas intenciones-. Desde una perspectiva de la Ciencia Ciudadana, tendrían que recibir otro tratamiento que no la simple descalificación como algo a ser descartado a favor de una versión hegemónica. Esta práctica traduce una visión de la ciencia que considera al ciudadano desprovisto de conocimientos válidos y los científicos como único por el emisor de saber legítimo. En esta perspectiva, es natural que el modelo informacional-comunicacional predominante sea marcadamente lineal y unidireccional, pautado por la transferencia, en que pesen las inmensas posibilidades multidireccionales y en red que las tecnologías digitales propician. Sin embargo, es por esas redes por donde circulan los "rumores", discursos que, enfrentados a los discursos oficiales, concurren por los sentidos de la vida, de la salud y de los derechos de ciudadanía. Un desafío, por lo tanto, es que las fuentes legitimadas desarrollen estrategias de producción discursiva que consideren el rumor más allá de entenderlo simplistamente como una no verdad. Por otro lado, han de considerar aquello que es designado como rumor como un flujo de anhelos, expectativas y memorias sociales, amplificado por las condiciones de contexto (como el escenario político y la incertidumbre científica, como vimos en el caso del zika). Los medios de comunicación tienen un lugar importante en esta competencia discursiva y si estuvieron ausentes en esta concurrencia de forma ostensible no fue por desconocer esa importancia, sino para evitar que la fuerza de su discusión pudiera desvelar las intenciones de las gentes. Dejemos claro, sin embargo, que el acto de designación como ejercicio de poder, siendo una práctica de los que tienen centralidad en el poder discursivo, por legitimidad o legalidad, es ejercido por los medios y en conjunto con los poderes públicos. Los medios de comunicación construyen los hechos y nombran a las personas y de esa forma manejan la 
comprensión de lo que ocurre en el mundo, teniendo una participación estructural en la producción de los sentidos de la salud y de todos los demás ámbitos de la vida social, colectiva e individual.

Reafirmamos que no asumimos un enfoque condescendiente en relación a la mentira, pero buscamos, a partir del tema de los rumores, ampliar la discusión en relación a las designaciones. Sin lugar a dudas, es un asunto que nos obliga a una mayor profundización, por su extrema complejidad y por su creciente importancia en la sociedad contemporánea. Hoy que se discute en todas los lugares el concepto de postverdad, esa discusión nos muestra que en nuestros tiempos y cada vez más no es una tarea trivial separar la cizaña del trigo, lo falso de lo verdadero. Por otra parte, las ideas de ciencia abierta y ciencia ciudadana cobran relieve al acoger formas de producción de conocimiento que puedan operar con formas más canónicas del hacer científico. Todo un desafío para la ciencia, y para nosotras como investigadoras.

\section{Agradecimientos}

Nuestros agradecimientos a los colaboradores João Verani Protasio (estudiante de Ciencias Sociales) y Roseanne Miranda (estudiante de Comunicación Social), becarios del Programa de Iniciación Científica del Consejo Nacional de Investigación (CNPq), en el Laboratorio de Investigación en Comunicación y Salud del Instituto de Comunicación e Información Científica y Tecnológica (LACES/Icict/Fiocruz), por la efectiva contribución intelectual en este artículo.

\section{Notas}

(1) Desde finales de 2015 muchos periodistas extranjeros ya se encontraban en el país, o al menos ya estaban con los ojos dirigidos al país debido a los Juegos Olímpicos, realizados en julio de 2016.

(2) Laboratorio de Investigación en Comunicación y Salud; Grupo de Investigación Comunicación y Salud (CNPq); Programa de Postgrado en Información y Comunicación en Salud, todos de la Fundación Oswaldo Cruz (Fiocruz).

(3) Instituto Oswaldo Cruz (IOC / Fiocruz).

(4) El concepto que desarrollamos también se aplica a otros elementos, por ejemplo, "interés público", o "política pública" (Araujo e Cardoso, 2007). Aquí nos detendremos sólo en la comunicación, al ser un escrito que tiene por objeto el ser publicado en una revista científica de comunicación.

\section{Referencias}

- $\quad$ Aguiar, R., Araujo, I.S. (2016). A mídia em meio às emergências do vírus Zika: questões para o campo da comunicação e saúde. Revista Electrônica de Comunicação, Informação e Inovação em Saúde, 10 (1). Recuperado de: https://www.reciis.icict.fiocruz.br/index. $\mathrm{php} / \mathrm{reciis/article/view/1088.}$

- American Press Institute. (2015). New fact-checking research: False information floods Twitter; many Americans "confidently wrong". Recuperado en: https://www.americanpressinstitute.org/fact-checking-project/new-fact-checking-research-false-information-floods-twitter-many-americans-confidently-wrong/.

- Araujo, I.S (2004). Mercado simbólico: um modelo de comunicação para políticas públicas. Interface - Comunicação, Saúde e Educação , Botucatu, SP, v. 8/14, p. 165-178, 2004.

- Araujo, I., Aguiar, R. (2017). O vírus Zika e a circulação dos sentidos: entre limites e res- 
sonâncias, apontamentos para uma pauta de pesquisa. In Castro, P.C. (Org.). A circulação discursiva: entre produção e reconhecimento. Maceió: EDUFAL.

- $\quad$ Araujo, I.S., Cardoso, J.M. (2007). Comunicação e Saúde. Rio de Janeiro: Editora Fiocruz.

- Bakhtin, M. (2006). Marxismo e filosofia da linguagem. São Paulo: HUCITEC.

- Bourdieu, P. (2011). O poder simbólico. Rio de Janeiro: Bertrand Brasil.

- Cardoso, J., Vaz, P. (2014). O drama epidêmico da dengue: causas, sofrimento e responsabilidades no Jornal Nacional (1986-2008). Revista Eco-Pós, 17, 1-13.

- Estratégia de Resposta ao Vírus Zika e Combate ao Mosquito Transmissor. (2016). Recuperado en http://www.casacivil.gov.br/.arquivos/estrategia-de-resposta-ao-virus-zika.pdf.

- Garcia, M. P. (2017). Disseram por aí: deu Zika na rede- rumors e produção de sentidos sobre a epidemia del zika e Microcefalia nas redes sociais (Dissertación de maestría, Instituto de Informação e Comunicação Tecnológica em Saúde-Icict/Ficoruz, Rio de Janeiro, Brasil).

- Manso, B.L.C. A comunicação pública da ciência à luz da ciência aberta: repensando o cidadão como sujeito informacional. XVI Encontro Nacional de Pesquisa em Ciência da Informação. João Pessoa (PB), 26 a 30 de outubro de 2015.

- Orlandi, E.P. (2010). As formas do silêncio: no movimento dos sentidos. Campinas: Editora Unicamp.

$\cdot$ (2012). Rumors e silêncios: os trajetos dos sentidos, os percursos do dizer. In Orlando, E.P., Discurso e texto: formulação e circulação dos sentidos. Campinas: Pontes.

- Pinto, M. J. (1994). As marcas linguísticas da enunciação: esboço de uma gramática enunciativa do português. Rio de Janeiro: Numen.

- Monteiro, G. F. (2007). A singularidade da comunicação pública. In Duarte, J. (Org.), Comunicação Pública: Estado, Mercado, Sociedade e Interesse Público. São Paulo: Atlas.

- Malinverni, C. (2017). Uma epizootia, duas notícias: a febre amarela como epidemia e como não epidemia. Revista Eletrônica de Comunicação, Informação \& Inovação em Saúde, 11 (2). Recuperado en https://www.reciis.icict.fiocruz.br/index.php/reciis/article/view/1339.

- Sá, N. (2015). Uma em cada 4 notícias publicadas no Twitter é falsa. Folha de S. Paulo. Recuperado de http://www1.folha.uol.com.br/mercado/2015/06/1645466-uma-em-cada4-noticias-no-twitter-e-falsa.shtml. 20/6/15.

- Sharma, M., Yadav, K., Yadav. N., Ferdinand, K. C. (2017). Zika virus pandemic: analysis of Facebook as a social media health information platform. American Journal of Infection Control, 45 (3), 301- 302.

- Verón, E. (1980). A produção do sentido. São Paulo: Cultrix.

- _ (2003). Fragmentos de um tecido. São Leopoldo: Ed. Unisinos.

- Wellcome Trust. (2016). Statement on Data Sharing in Public Health Emergencies. Recuperado en https://wellcome.ac.uk/press-release/global-scientific-community-commits-sharing-data-zika. 


\section{CURRICULUM VITAE}

\section{Inesita Soares de Araujo}

Doctora en Comunicación y Cultura, con postdoctorado en Ciencias Sociales. Investigadora titular en el Laboratorio de Investigación en Comunicación y Salud del Instituto de Comunicación e Información Científica y Tecnológica /Fundación Oswaldo Cruz, donde coordina el Observatorio Salud en los Medios. Miembro del cuerpo docente y orientadora de tesis del Programa de Postgrado en Información y Comunicación en Salud (Icict/Fiocruz). Coordinadora del GT Comunicación y Salud de la Asociación Latinoamericana de Investigadores de la Comunicación (ALAIC) y del GT Comunicación y Salud de la Asociación Brasileña de Salud Colectiva (ABRASCO). Líder de lo grupo de investigación Comunicación y Salud (CNPq).

\section{Raquel Aguiar}

Periodista, doctora por el Programa de Post-Graduación en Información y Comunicación en Salud del Instituto de Comunicación e Información Científica y Tecnológica en Salud (Icict/ Fiocruz). Coordinadora de comunicación social del Instituto Oswaldo Cruz (IOC/Fiocruz) y coordinadora adjunta del Observatorio Salud en los Medios de Comunicación. Miembro del Grupo de Investigación Comunicación y Salud y del Grupo de Investigación Midiatización de las Prácticas Sociales del Consejo Nacional de Investigación. Miembro de de la Asociación Brasileña de Salud Colectiva (ABRASCO). 


\section{DIVULGATION ARTICLES ARTÍ́CULOS DE DIVULGACIÓN}
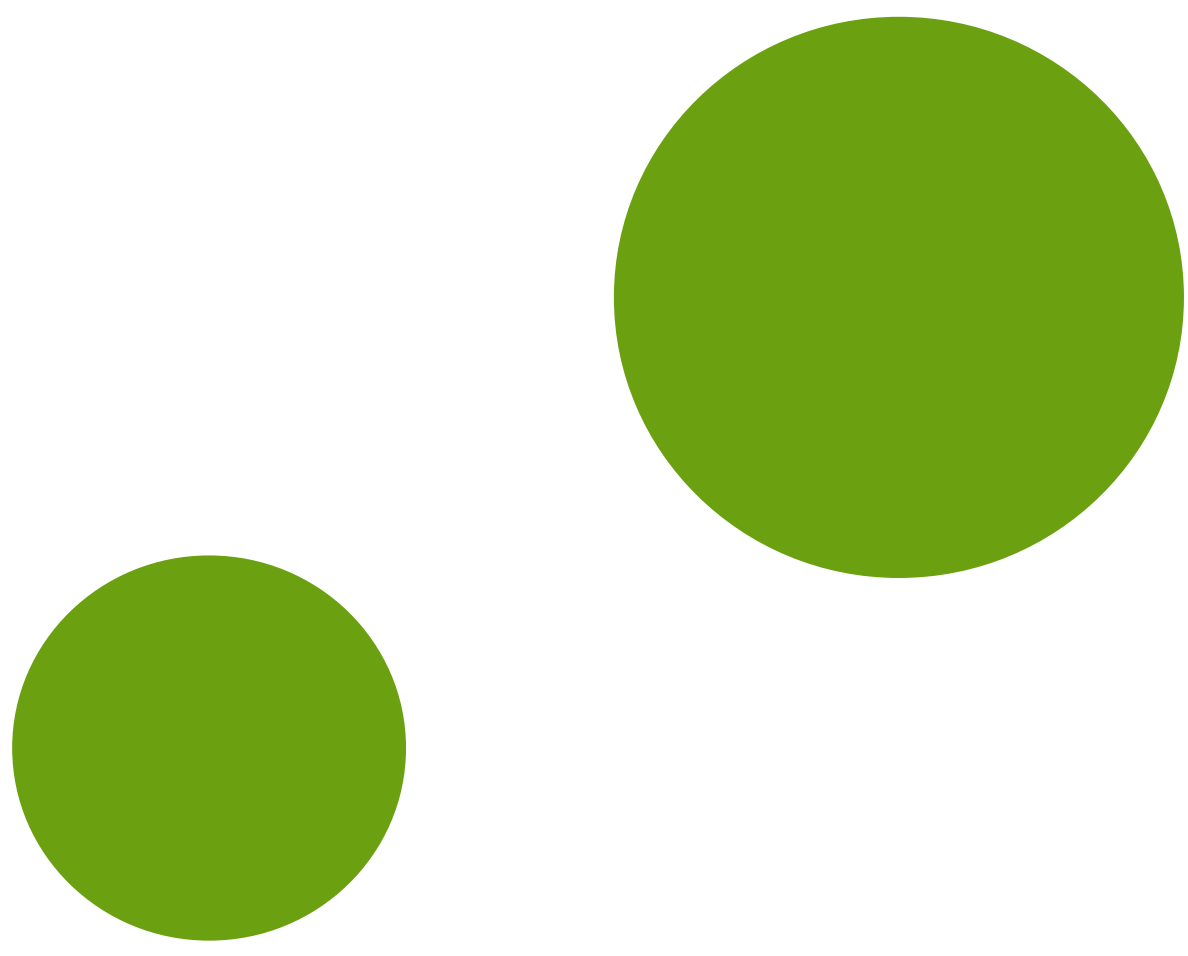
